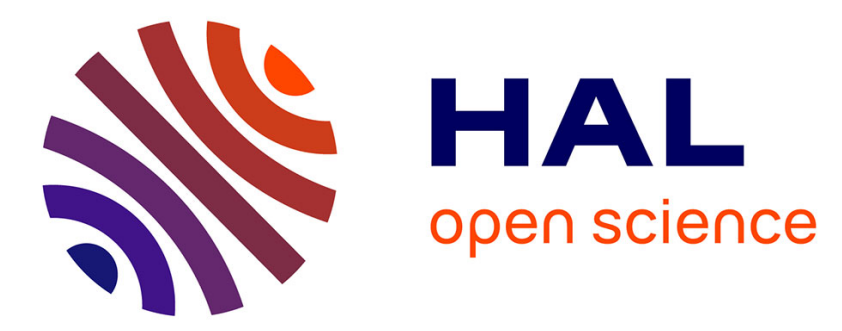

\title{
Evidence of phase nucleation during olivine diffusion creep: A new perspective for mantle strain localisation Jacques Précigout, Holger Stünitz
}

\section{To cite this version:}

Jacques Précigout, Holger Stünitz. Evidence of phase nucleation during olivine diffusion creep: A new perspective for mantle strain localisation. Earth and Planetary Science Letters, 2016, 455, pp.94-105. 10.1016/j.epsl.2016.09.029 . insu-01378558

\section{HAL Id: insu-01378558 \\ https://hal-insu.archives-ouvertes.fr/insu-01378558}

Submitted on 10 Oct 2016

HAL is a multi-disciplinary open access archive for the deposit and dissemination of scientific research documents, whether they are published or not. The documents may come from teaching and research institutions in France or abroad, or from public or private research centers.
L'archive ouverte pluridisciplinaire HAL, est destinée au dépôt et à la diffusion de documents scientifiques de niveau recherche, publiés ou non, émanant des établissements d'enseignement et de recherche français ou étrangers, des laboratoires publics ou privés.

\section{(1) (1) $\$$}

Distributed under a Creative Commons Attribution - NonCommercial - NoDerivatives $\mid 4.0$ 


\title{
Evidence of phase nucleation during olivine diffusion creep: A new perspective for mantle strain localisation
}

\author{
${ }^{1}$ Jacques Précigout* and ${ }^{1,2}$ Holger Stünitz
}

${ }^{1}$ Institut des Sciences de la Terre d'Orléans (ISTO), UMR-CNRS 7327, Université d'Orléans, 1 A rue de la Férollerie, 45071 Orléans, France.

${ }^{2}$ Department of Geology, University of Troms $\varnothing$, Dramsveien 201, 9037 Troms $\varnothing$, Norway

* To whom correspondence should be addressed: jacques.precigout@ univ-orleans.fr;

$+33(2) 38255391$

Key words:

- Griggs-type experiments

- Mantle rheology

- Poly-phase material

- Lithosphere

- Creep cavitation 


\section{Abstract}

For the past decades, grain size reduction leading to diffusion creep in olivine is believed to be a very important process for strain localisation in the lithospheric mantle. However, the mechanisms of grain size reduction in this regime are still poorly understood (e.g., Platt, 2015). Here we show new experimental results that document grain size reduction and material weakening during wet olivine diffusion creep. While occurring for both, mono-phase and twophase aggregates, grain size reduction is coeval with strain localisation and local phase mixing in olivine-pyroxene aggregates. Based on evidence of fluid inclusions and cracks filled with a fine-grained phase mixture, we conclude that grain size reduces as a result of fluid-assisted nucleation that takes place in the presence of an aqueous fluid during diffusion creep. Cavitation induced by grain boundary sliding (creep cavitation) can be inferred, and may play a critical role for olivine grain size reduction. Amongst their implications for rock rheology in general, our findings highlight a key process for strain localisation in the ductile uppermost mantle.

\section{Introduction}

In order for tectonic plates to be isolated from each other by high-strain plate boundaries, such as subduction zones or narrow rifts, strain localisation has to occur across the strong uppermost mantle (Burov and Watts, 2006; Bercovici and Ricard, 2014). The deformation of the lithosphere strongly depends on this presence or absence of strain localisation. Although some brittle behaviour may be expected in the shallow mantle, extrapolations of lab-based flow laws to corresponding depths give predictions of the uppermost mantle as mostly plastic (Kohlstedt et al., 1995). In this regime, strain localisation typically arises from a local weakening of the deforming rock, the origin of which remains very elusive today.

Olivine is by far the most abundant phase in the upper mantle. For this reason, experimental, field-based, and modelling studies have focussed on the role of olivine for mantle rheology in the last 
decades, concluding that grain size reduction and dominant diffusion creep may be the best candidate to account for quasi-viscous strain localisation (Rutter and Brodie, 1988; Drury et al., 1991; Bercovici and Ricard, 2012). Their conclusion is based on the fact that (1) grain size reduction is a ubiquitous feature of ductile shear zones, and (2) diffusion creep (including grain boundary sliding) is grain size sensitive, unlike dislocation creep which does not - or to a lesser extent in the case of disGBS (Hansen et al., 2011) - depend on grain size (Karato et al., 1986; Hirth and Kohlstedt, 2003). However, grain size reduction is not a process which is defined or understood during dominant diffusion creep (e.g., Rutter and Rrodie, 1988; De Bresser et al., 2001). Thus, although reducing grain size in this regime may be a key factor for strain localisation (Rutter and Brodie, 1988; Bercovici and Ricard 2012; Platt, 2015), the processes are poorly known and require further investigation.

Many studies have pointed out the presence of minor phases, such as micas or pyroxenes, as a condition for small grain sizes during grain-size-sensitive creep (Hiraga et al., 2010; Herwegh et al., 2011; Farla et al., 2013; Linckens et al., 2014; Platt, 2015). Most of them attributed the reduction of grain size to a combination of dynamic recrystallization and grain boundary sliding (GBS), resulting in phase mixing. Following this approach, Bercovici and Ricard (2012) developed a theoretical model to propose that damages at olivine-pyroxene interfaces would indirectly drive grain size to reduction, provided that grain boundary pinning (Zener pinning) arises from phase mixing. However, natural evidence of grain size reduction induced by pinning of grain boundaries is still lacking; Zener pinning has been only shown to inhibit grain growth, not reducing grain size (Stünitz and FitzGerald, 1993; De Ronde et al. 2005; Warren and Hirth, 2006; Sundberg and Cooper, 2008). Furthermore, the link between phase mixing, grain size reduction and GBS during diffusion creep, as well as the transition from dislocation creep to diffusion creep, is still unclear (Dimanov and Dresen, 2007; Kilian et al. 2011; Platt, 2015). And not all aspects are supported by available data. In recent high-temperature $\left(>1200^{\circ} \mathrm{C}\right)$ experiments on two-phase material (olivine + pyroxene), it has been 
shown that diffusion creep tends to aggregate phases because of its related component of GBS, promoting grain growth instead of grain size reduction (Hiraga et al., 2013).

In this study, we show new experimental results that document grain size reduction during diffusion creep in olivine at wet conditions of the uppermost mantle. The reduction can be understood in the presence of second phases, but not necessarily; we document it for both mono-phase (olivine) and two-phase (olivine + pyroxene) aggregates. In presence of pyroxene, strain localisation also goes along with grain size reduction and gives rise to typical ductile shear zones where complete phase mixing occurs. Both chemical and microstructural features suggest that grain size reduction results from fluid-assisted nucleation of olivine and pyroxene grains.

\section{Material and methods}

\subsection{Sample preparation}

In all experiments, we used olivine (Fo91) from San Carlos (Arizona, USA) and clinopyroxene (Wo51 $\left.\mathrm{En}_{48} \mathrm{Fs}_{1}\right)$ from Cranberry lake (Canada). To produce the starting material, we crushed gemquality single crystals in an agate mortar and sorted the grain size using a decantation method with distilled water. For olivine, we used a grain size ranging from 1 to $10 \mu \square$ with a mean of $2 \mu \square$ in all experiments. As for clinopyroxene ( $\mathrm{CPx})$, two types of grain sizes were used: one with fine $\mathrm{CPx}$ between 5 and $20 \mu \square$, and a second one with coarser CPx grains between 40 and $125 \mu \square$. Olivine and pyroxene powders were mixed at a ratio of 70 to $30 \%$ (by weight) in a solution of ethanol, following the procedure described in de Ronde et al. (2005). The powder was then placed between two alumina shear pistons cut at $45^{\circ}$ to the piston axis, wrapped in a nickel foil and enclosed in a platinum jacket welded at both ends. The shear piston surfaces have been previously roughened using 120-grit corundum paper. Before welding, 0.1 or 0.2 wt.\% of distilled water were added. These amounts exceed the solubility of water in olivine and pyroxene at our experimental conditions (Zhao et al., 2004; Bromiley et al., 2004). Such wet conditions and grain size have been chosen to ensure that (1) olivine will deform in the diffusion creep regime (Hirth and Kohlstedt, 2003; Sunderg and 
Cooper, 2008; Hansen et al., 2011), and (2) initial grains will be large enough to see significant grain size reduction, if applicable. We also have chosen to use clinopyroxene - instead of orthopyroxene to ensure that secondary phases will be stronger than the olivine matrix (Bürgman and Dresen, 2008). Few grains of orthopyroxene (enstatite; $\sim 0.2$ wt. $\%$ ) and amphibole (tremolite; $\sim 0.8$ wt. $\%$ ) were present in the CPx powder despite initial handpicking (fig.1).

\subsection{Deformation experiments}

The deformation experiments were conducted in a solid medium $(\mathrm{NaCl})$ Griggs-type apparatus at Troms $\emptyset$ University (Norway). Temperature and pressure were alternately increased over several hours up to the conditions of experiment $\left(900^{\circ} \mathrm{C}\right.$ and $\left.1.2 \mathrm{GPa}\right)$. Samples were hot-pressed in situ for $24 \mathrm{~h}$ (microstructures of hot-pressed material are available in supplementary figure 1). The deformation piston ( $\sigma_{1}$-piston) was then advanced at a constant rate, first through the top lead piece, and then touching the alumina piston (fig.1A). Samples started to deform at this point, several hours after starting to advance the $\sigma_{1}$-piston. At the end of the experiment, the samples were quenched from $900^{\circ} \mathrm{C}$ to $200^{\circ} \mathrm{C}$ in 2 minutes. Both, pressure and differential stress decreased rapidly until the temperature stabilised at $200^{\circ} \mathrm{C}$. Subsequently, the sample was decompressed at a rate of $\sim 5 \mathrm{MPa}$ per minute, keeping the differential stress $\sim 100 \mathrm{MPa}$ above the confining pressure to reduce the formation of unloading cracks. Finally, temperature was dropped to $30^{\circ} \mathrm{C}$ when the confining pressure was lower than $100 \mathrm{MPa}$. After the experiment, the samples were impregnated with epoxy, and then sectioned along the piston axis for thin sections.

\subsection{Analytical procedures}

Sample microstructures were analysed with a scanning electron microscope (SEM) of ISTO/BRGM (Orléans, France) and a transmission electron microscope (TEM) at the University of Minnesota (Minneapolis, USA). SEM work has been performed on carbon-coated (20 nm thickness) thin section using a TESCAN MIRA 3 XMU at $25 \mathrm{kV}$ and a working distance of $25 \mathrm{~mm}$. TEM images 
were taken using a FEI-TECNAI T12 at $120 \mathrm{kV}$ through a focused ion beam (FIB) foil of 50-100 nm thickness. In the TEM, Energy dispersive X-ray spectroscopy (EDS) was used to analyse phases. Electron backscatter diffraction (EBSD) was employed for Lattice Preferred Orientation (LPO) and grain size determination on polished surfaces (diamond paste of $0.25 \mu \mathrm{m}$ followed by colloidal silica) with an EDAX Pegasus system at $25 \mathrm{kV}$ and a working distance of $18 \mathrm{~mm}$. Lower-hemisphere pole figures of LPO were constructed considering both, the whole map dataset (available in supplementary figure 2) and one measurement per grain acquired manually. The data from EBSD maps have been processed with the OIM ${ }^{\mathrm{TM}}$ - EDAX software, and the grain size distributions are shown with respect to the percent area of each category in order to compare between sample types. For LPO, the texture (J) and misorientation (M) indices are also given, which both quantify the degree of minerals alignment between $\mathrm{J}=1 / \mathrm{M}=0$ for a uniform distribution, and $\mathrm{J}=\infty / \mathrm{M}=1$ for a crystal-like distribution considering one point per grain (Bunge, 1982; Skemer et al., 2005). Phase composition, including starting material, was measured with an electron microprobe CAMECA SX five at ISTO on carbon-coated (20 nm thickness) thin sections at $15 \mathrm{keV}$ and $10 \mathrm{nA}$. The step size of the microprobe map was $0.5 \mu \mathrm{m}$.

To measure in situ water content of both olivine and pyroxene grains, we performed ion probe measurements on gold-coated (20 nm thickness) thin sections using a Cameca IMS 1280-HR at the CRPG (Nancy, France). A primary beam of $\mathrm{Cs}^{+}$was used with a current of $3 \mathrm{nA}$ and a beam diameter of $10 \mu \mathrm{m}$. The positive secondary beam was centred in a $2500 \mu \mathrm{m}$ image field aperture. The voltage offset was stable at $-50 \mathrm{eV}$ and the energy window has been set to $20 \mathrm{eV}$. The counting elements were ${ }^{16} \mathrm{O},{ }^{17} \mathrm{O},{ }^{16} \mathrm{OH},{ }^{17} \mathrm{OH},{ }^{28} \mathrm{Si}$ and ${ }^{30} \mathrm{Si}$ with a counting time between $3 \mathrm{~s}$ (for $\mathrm{Si}$ ) and $12 \mathrm{~s}$ (for $\mathrm{OH}$ ). The total counting time was 12 minutes per point. To calibrate the ratio $\mathrm{H} / \mathrm{Si}$, we used the ratio $\mathrm{H}_{2} \mathrm{O} / \mathrm{SiO}_{2}$ from standards, including basaltic glass (M35, M40, M48, T1G, StHs, K12G), synthetic forsterite ( $\mathrm{Fo}_{100}$ ), clinopyroxene (cpxNSH), pyrope (MON 9) and quartz (Suprasil). The very good quality of 
vacuum into the chamber $\left(6-7 * 10^{-10}\right.$ torr) indicated that no epoxy degassing occurred during the analyses.

\section{Results}

\subsection{Mechanical data}

The strain-stress curves of all experiments show an increase of differential stress to peak stress at a bulk shear strain of $\gamma \approx 1$ (fig.1B). While the peak stress of the pure olivine sample reaches $\sim 550$ $\mathrm{MPa}$, the one of the two-phase samples ranges above $750 \mathrm{MPa}$. These data indicate stronger samples when CPx is present, in agreement with previous data for pyroxene strength (Dimanov and Dresen, 2007; Dimanov et al., 2007; Chen et al., 2006). Following the peak stress, the differential stress drops progressively toward a steady-state stress of around $300 \mathrm{MPa}$ for both, the pure olivine sample and two-phase samples with fine-grained CPx. In contrast, from $\gamma \square \square \square 2.5$ onward, the sample with coarse-grained CPx stabilises at a steady-state stress of $700 \mathrm{MPa}$ until the end of the experiment.

\subsection{Microstructures and composition}

The main difference between mono- and two-phase aggregates is the occurrence or absence of strain localisation. While the pure olivine sample shows homogeneous deformation (fig.1C and supplementary figure 3), the strain in composite samples is localised to different degrees depending on the initial grain size of CPx. In presence of coarse CPx $(40-125 \mu \mathrm{m})$, strain is highly localised within a $\sim 50 \mu \mathrm{m}$ wide shear zone, which is well developed on the sample side near the piston corner (fig.1D). In contrast, the presence of fine-grained CPx $(\sim 2 \mu \mathrm{m})$ by the same proportion $(30 / 70 \%)$ promoted strain to localise into a shear zone of $\sim 150 \mu \mathrm{m}$ width all through the sample (fig.1E). Samples deformed to only peak stress conditions do not show significant deformation, so that it can 
be inferred that strain localisation takes place from peak stress conditions onwards during weakening of the sample.

Furthermore, using the angle $(\theta)$ between the shear plane (piston interface) and foliation plane (long axis of CPx porphyroclasts), and the relationship: $\gamma=2 / \tan 2 \theta$ (Ramsay, 1980), we have estimated the strain gradients in both types of composite samples. With coarse CPx, strain ranges from a minimum of $\gamma \approx 0.2$ near the shear piston to $\gamma \square \square \square \square \square$ in the 50 - $\mu$ m-thick localised shear zone (fig.1D). With fine CPx, strain reaches $\gamma \square \square \square \square \square$ in the $150-\mu \mathrm{m}$-thick localised shear zone, but we also see the development of strain partitioning with typical shear bands parallel to the shear plane where strain is higher (fig.1E). Considering the amount of displacement accommodated by the bulk sample over the time of experiment from the peak stress onward (see supplementary table 1), i.e., considering plastic strain only, we can estimate a shear strain rate of $\sim 10^{-4} \mathrm{~s}^{-1}$ in the $50-\mu \mathrm{m}$-thick shear band and $\sim 5.10^{-5} \mathrm{~s}^{-1}$ in the $150-\mu \mathrm{m}$-thick one.

The two-phase mixture that develops at olivine-pyroxene clast interfaces is of particular interest. This phase mixture mostly typically forms thin layers which extend from the tip or side of CPx grains through the olivine matrix (fig. $1 \mathrm{~F}-\mathrm{H})$. Strain is highly localised in these layers. In samples with fine-grained CPx, the mixture has a grain size lower than or equal to $1 \mu \mathrm{m}$, and it occurs directly in contact with the porphyroclasts of CPx. In contrast, the coarse-grained CPx clasts develop inner tails that consist of 1 to $2 \mu \mathrm{m}$ sized grains of pure CPx (fig. $1 \mathrm{~F}$ ). These inner tails are mantled by elongated tails of a two-phase, intimately-mixed material of olivine and CPx. TEM observations indicate a grain size of 0.1 to $0.2 \mu \mathrm{m}$ for all phases of the mixture, whereas the adjacent olivine matrix reveals a homogeneous grain size with equiaxed grains of $\sim 1 \mu \mathrm{m}$ (fig.2A-B). The fine-grained material consists of well-mixed olivine and clinopyroxene with a very few grains of enstatite. There are no dislocations in the layers of fine-grained mixture, but dislocations are present in the larger grains of the olivine matrix (fig.2B).

In addition, cracks occur in the olivine matrix (fig.2C) and at the high-stress sides of CPx clasts (fig.2D). While new grains of olivine are present in cracks of the olivine matrix (fig.2C), the 
CPx cracks are filled with a fine-grained mixture of olivine $+\mathrm{CPx}$. Most of these CPx cracks contain one or more fluid inclusions at their tip, highlighting the presence of a free fluid phase during deformation (fig.2E-F).

In terms of composition, the phase mixture is too fine grained to measure the composition of individual grains by the electron microprobe. As a consequence, the integrated measurements of the phase mixture have an intermediate composition which ranges between the two end-members of single-phase olivine and diopside, as shown in figures $3 \mathrm{~A}$ and $3 \mathrm{~B}$. We do not see any chemical effect of the presence of enstatite, suggesting that enstatite grains result from local equilibrium. During deformation, the compositions of both, olivine and diopside, have shifted slightly with respect to the starting material in monomineralic domains: olivine becomes more magnesium-( $\mathrm{Mg})$ rich, and $\mathrm{CPx}$ more iron (Fe)-rich (fig.3C and 3D). The calcium (Ca) content of CPx decreases slightly, whereas Ca in olivine records some enrichment (fig.3D). Analyses of individual grains in the TEM show a larger variation in olivine and CPx grains in the mixture compared to olivine in monomineralic layers (fig.3E). We attribute these compositional changes to element exchange that tends to locally equilibrate the olivine and pyroxene compositions at $900^{\circ} \mathrm{C}$ and $1.2 \mathrm{GPa}$.

\section{$3.3 \mathrm{H}_{2} \mathrm{O}$ content}

The ion probe dataset documents water-rich olivine grains with $\sim 157 \pm 44$ wt. ppm $\mathrm{H}_{2} \mathrm{O}$ and pyroxene grains with $\sim 147 \pm 63$ wt. ppm $\mathrm{H}_{2} \mathrm{O}$ (table 1 ). Within error, these values correspond to the water solubility of olivine and pyroxene at $900^{\circ} \mathrm{C}$ and $1.2 \mathrm{GPa}$, which have been estimated at 155 and 150 wt. ppm $\mathrm{H}_{2} \mathrm{O}$, respectively (Kohlstedt et al., 1996; Bell et al., 2003; Zhao et al., 2004; Bromiley et al., 2004). There is one exception of deformed CPx in the shear zone of composite samples where more than 400 wt. ppm $\mathrm{H}_{2} \mathrm{O}$ are recorded, possibly because of the presence of sub-microscopic fluid inclusions.

All analyses that include grain boundaries yield higher water contents, typically between 300 and 800 wt. ppm $\mathrm{H}_{2} \mathrm{O}$. In specific areas, we also measured more than 900 wt. ppm $\mathrm{H}_{2} \mathrm{O}$. This includes 
1) the surrounding matrix of amphibole grains, and 2) the shear zones where the density of grain boundaries substantially increased because of grain size reduction (table 1). While the former indicates that amphibole grains released some water during experiment - tremolite is metastable at $900^{\circ} \mathrm{C}$ and $1.2 \mathrm{GPa}$ (Jenkins, 1983) - the latter suggests that grain boundaries contain a significant amount of water. As suggested by the presence of fluid inclusions, our ion probe data confirms that deformation occurred in water-saturated conditions during the experiments.

\subsection{Mineral LPO and grain size}

The olivine LPOs presented here have been obtained from pure olivine layers only, regardless of the sample type. For composite samples, we focussed on olivine in shear zones. In the hot-pressed sample, the olivine LPO is nearly random with very low texture and misorientation indices of $\mathbf{J}=$ 1.48 and $\mathrm{M}=0.017$ (fig.4). With deformation, an olivine LPO starts to develop at peak stress conditions, and then moderately strengthens with increasing strain, except for the shear zone with $\gamma$ $>10$ (coarse CPx) where no clear pattern of LPO is observed. In any case, the texture and misorientation indices remain extremely low and never exceed $\mathrm{J}=2$ and $\mathrm{M}=0.1$, regardless of both, the finite strain and presence or absence of CPx (fig.4). In terms of geometry, the fabric has the [001] axis close to the shear direction and the [010] axis normal to the shear plane, typical of so-called Btype fabric (Jung and Karato, 2001).

Olivine grain size reduction occurs for both, mono-phase and two-phase aggregates, but only after the peak stress. Indeed, the grain sizes at peak stress conditions shows a log-scale distribution and remains unchanged with respect to the hot-pressed sample; we document a mean grain size of $\sim 2$ $\mu \mathrm{m}$ and a mode of $\sim 3 \mu \mathrm{m}$ for both samples (fig.5). In contrast, grain size has been significantly reduced to a mean and mode of $\sim 1.5 \mu \mathrm{m}$ in the pure olivine sample $(\gamma=2.5)$ and in the shear zone of the two-phase samples with fine-grained $\mathrm{CPx}(\gamma>5)$. The shear zone with coarse-grained $\mathrm{CPx}(\gamma>$ 10) even records a grain size reduction with a mean size and mode of $1.1 \mu \mathrm{m}$ (fig.5). Furthermore, 
with increasing strain, there is an increase from 10 to $16 \%$ of the maximum area fractions, indicating that grain size becomes more uniform during deformation.

It is apparent in figure 6 that new olivine grains appear randomly distributed within the olivine matrix. Based on EBSD maps in combination with inverse pole figures (color coding with respect to the shear direction $X)$, we show that the crystal orientation of small grains $(<1 \mu \mathrm{m})$ differs from one grain to another, as well as from the neighbouring olivine porphyroclasts by at least 30 degrees (fig.6A). Thus, new olivine grains neither have any crystallographic relationship with one another nor with the larger ones. Furthermore, most of these small grains are isolated and dispersed randomly within the olivine matrix, and the amount of larger olivine grains $(>3 \mu \mathrm{m})$ decreases with increasing strain. These large grains disappear entirely in the high-strain shear zone $(\gamma>10)$, whereas the amount of grains smaller than $1 \mu \mathrm{m}$ significantly increases (fig.6B).

In samples with fine-grained $\mathrm{CPx}(\gamma>5)$, the new pyroxene grains occur as mixed with olivine and have a grain size lower than or equal to $1 \mu \mathrm{m}$. They develop a weak LPO $(\mathrm{J}=1.94 ; \mathrm{M}=0.024)$ with the [001] axis close to the shear direction and (010) plane within the shear plane (fig.6C). These observations are consistent with the fact that the fine-grained CPx grains do not have any crystallographic relationships with respect to each other (fig.6D). We did not see any tails of pure CPx in these samples. In contrast, the sample with coarse-grained CPx $(\gamma>10)$ developed inner tails of CPx aggregates with a mean grain size around $1.4 \mu \mathrm{m}$. They show a strong preferred orientation $(\mathrm{J}>28 ; \mathrm{M}>0.34)$, which is directly related to the orientation of the starting porphyroclast (fig.6D). Thus, all grains composing a single tail in coarse CPx have a similar crystallographic orientation as 
the starting CPx (fig.6F). Note that we do not document any LPO in layers of phase mixture that extend from these tails because the grain size was too small $(\sim 0.1 \mu \mathrm{m})$ to be indexed at the EBSD.

\section{Discussion}

\subsection{Phase mixing and nucleation}

In our experiments, the production of very fine-grained olivine-CPx mixture and high strain deformation typically are joint features. Moreover, our documentation of CPx cracks filled by a phase mixture (fig.2) provides a key evidence for understanding how the phase mixture forms. The crack filling consists of approximately equal proportions of very small $\mathrm{Cpx}$ and olivine grains. The local nature of this filling demonstrates that both, olivine and pyroxene, have nucleated together at the same time during opening of the cracks. The presence of fluid inclusions and our ion probe dataset also indicate that a fluid phase was present during deformation. And the geometry and orientation of cracks (mode 1 cracks) suggest that phase nucleation is connected to a local stress drop. We do not exclude that the crack geometry could also be crystallographically-controlled.

In these cracks, phase mixing cannot result from a two-stage-process involving first the formation of the small grains, and then a mixing process by, e.g., grain boundary sliding (GBS) as proposed by Farla et al. (2013) and Linckens et al. (2014). The nature of the local mixture also excludes dynamic recrystallization. Instead, it is likely that phase mixture formed by simultaneous nucleation of the two phases (fig.7), giving rise to filling of low-stress sites, where, once formed as a single-stage process, very small grain sizes are preserved because of grain boundary pinning. The presence of an aqueous fluid makes it likely that the two phases precipitated from a fluid. The same grain size and distribution of phases in mixture layers extenting from the CPx porphyroclasts (fig.1) suggest that these layers result from the same fluid-assisted nucleation process as the crack fills.

The occurrence of fine-grained, intimately-mixed phases in two- or poly-phases material is commonly observed in the core of mantle shear zones, particularly where strain has been highly localised (Warren and Hirth, 2006; Toy et al., 2010; Drury et al., 2011; Linckens et al., 2014). The 
source mechanism of this mixing remains very uncertain so far. As summarised in Platt (2015), recent field studies suggested that the GBS component of diffusion creep might account for it, but recent high-temperature deformation experiments of olivine + pyroxene aggregates in the diffusion creep regime do not support GBS as the source of mixing; grain neighbour switching helps to aggregate phases rather than disperse them (Hiraga et al., 2013).

According to different authors, phase mixing may be the result of solid-melt interactions (Dijkstra et al., 2002), or sub-solidus phase transformation (Newman et al., 1999; de Ronde et al., 2005). But the pressure-temperature conditions of our experiments exclude melting, and both, olivine and clinopyroxene, are stable in these conditions. As an alternative, the process of fluid-assisted nucleation we described above may account for some observed phase mixing in nature, particularly for low-temperature shear zones where dissolution-precipitation commonly occurs (e.g., Herwegh et al., 2011). We do not exclude either that chemical adjustment to local equilibrium - in combination with dissolution-precipitation - could be one of the driving potentials for nucleation.

\subsection{Olivine fabric and diffusion creep}

In our samples, the strength ( $\mathrm{J}$ and $\mathrm{M}$ indices) of the B-type olivine fabric moderately increases up to $\gamma>5$ in olivine layers, but it remains very weak and the B-type fabric does not show up anymore at $\gamma>10$ (fig.4). In any case, we document extremely weak LPOs considering the amount of strain accommodated. For instance, one would expect $\mathrm{J}>10$ and $\mathrm{M}>0.3$ for a gamma strain higher than 3 (Hansen et al., 2014; Mainprice et al., 2015), whereas we never quantify higher than J = 2 and $\mathrm{M}=0.1$, irrespective of the amount of finite strain.

While a strong LPO is typical of dominant dislocation creep (or disGBS; Hansen et al., 2012), a weak or absent LPO despite intense finite strain commonly indicates diffusion creep deformation

(including GBS; Fliervoet et al., 1999; Drury et al., 2011; Herwegh et al., 2011). Furthermore, Sundberg and Cooper (2008) have shown that B-type fabric may occur during olivine diffusion creep, and especially in presence of (ortho)pyroxene. Based on numerical results (Bons and den Brok, 2000), 
they attributed the B-type fabric to the GBS component of diffusion creep when accommodated by anisotropic lattice-controlled grain boundary migration. The recent experiments of Miyazaki et al. (2013) on olivine diffusion creep further support this point. In our samples, the presence of very weak B-type fabric is therefore consistent with olivine deforming by diffusion creep in combination with GBS. Again, it should be noted that the weak LPO forms in pure olivine aggregates and not in mixture layers, where the grain size was too small $(<0.2 \mu \mathrm{m})$ to be indexed at the EBSD. It is also probable that fine-grained CPx deformed by diffusion creep based on their weak LPO (fig.6C). In contrast, the strong, host-controlled LPO of the inner tails of CPx involves dominant dislocation creep and related dynamic recrystallization, probably by sub-grain rotation.

\subsection{Grain size reduction}

In this study, we document grain size reduction after peak stress during substantial weakening of the sample strength (fig.5). This reduction occurs for olivine and CPx grains in both, mono-phase and two-phase aggregates. Based on the strong LPO, we inferred grain size to be reduced by dynamic recrystallization in the inner parts of large CPx tails (figs.2 and 6). However, dynamic recrystallization did not produce the very fine-grained mixture of olivine and CPx. And we inferred from our microstructural features that the phase mixture results from nucleation, probably fluidassisted.

In addition, based on available flow laws for wet olivine (Hirth and Kohlstedt, 2003; Hansen et al., 2011), we show that grain size reduction of the pure olivine sample took place in the diffusion creep field along the strain rate isolines. The olivine grain size of both, pure olivine layers and mixture layers, in the two-phase samples also falls within the diffusion creep field, which supports again dominant diffusion creep for olivine (fig.8). In all cases, grain size reduction occurred below the experimentally calibrated olivine piezometer (Van der Wal et al., 1993), which defines the stressgrain size relationships for dynamically recrystallized grains as dictated by the rate of mechanical work (Austin and Evans, 2007). Ever if we consider the occurrence of bulging (Platt and Behr, 2011), 
the mean grain size of deformed olivine aggregates stands below the minimum size of bulge (dotted line in fig.8). Thus, dynamic recrystallization has not contributed in reducing olivine grain size. As a possible alternative, Zener pinning is effective in maintaining the small size of grains in mixed layers. This mechanism has been proposed as potentially able to reduce grain size below the piezometer (Bercovici and Ricard, 2012). However, in absence of pyroxene grains in the olivine matrix (the nonmixed parts), and of course, for the pure olivine sample, a mechanism other than Zener pinning is required.

\subsection{Creep cavitation as a potential origin for grain size reduction}

During dominant diffusion creep, the deformation of poly-crystalline material involves a component of grain boundary sliding (GBS; e.g., Langdon, 2006). If crystal-plastic or diffusional mass transport processes cannot accommodate the local sliding of grains fast enough, GBS may lead to the formation of micro-cavities which open (and may close again), giving rise to a process termed creep cavitation (Kassner and Hayes, 2003; Dimanov et al., 2007). In nature, this mechanism is coeval with phase nucleation resulting from dissolution-precipitation (Fusseis et al., 2009; Kilian et al., 2011; Herwegh et al., 2011). Such a nucleation process is a viable mechanism for reducing grain size in the diffusion creep domain and will depend on the solubility of rock components. Based on our evidence of nucleation in micro-cracks, we therefore propose that grain refinement has occurred in pure olivine layers by nucleation in sites produced by creep cavitation.

In this view, nucleation in dilatant sites is expected to yield small, randomly oriented grains, which may subsequently grow at the expense of the old ones with a preferred orientation, reducing grain size and randomising the mineral LPO (fig.9A). The small size of these new grains assures the operation of GBS as their dominant deformation mechanism. If the nucleation rate is high enough, GBS does not produce any LPO, because the grains are continuously renewed with random orientations. In contrast, at moderate or low nucleation rates, the new grains do not sufficiently decrease the pre-existing fabric, giving rise to a preferred orientation (e.g., B-type fabric), the strength 
of which depends on the nucleation rate. Such a nucleation model accounts for (1) grain size reduction within the diffusion creep field, (2) the dispersion of new olivine grains within the olivine matrix, (3) the absence or weak LPO despite high strain deformation, and (4) the occurrence of phase mixing at phase interfaces (fig.9B). This process is relatively easy to detect if nucleation of mixed phases occurs (e.g., Kilian et al., 2011; Platt, 2015), but in the case of a single-phase aggregate with the same phase nucleating, it is more difficult and requires at least a LPO analysis.

\subsection{Implications for strain localisation}

The nucleation of new grains as a process of grain size reduction during dominant diffusion creep highlights a potentially important source for weakening and strain localisation, provided that grain size reduction is locally enhanced. In our experiments, strain only localises in two-phase aggregates where strong and locally cracked CPx clasts are present. The occurrence of mode-1-cracks at the rim of CPx porphyroclasts suggests that stress locally increased during deformation. As shown during creep cavitation of metals, micro-cavities form most easily at sites of higher stresses (Kassner and Hayes, 2003). Thus, it is likely that the pure olivine matrix adjacent to CPx porphyroclasts suffered more creep cavitation and phase nucleation, enhancing grain size reduction (fig.9C). This would promote local weakening and subsequent strain localisation within the olivine matrix. We also envisage that strain localisation propagates because of stress concentration (shear stress) and related creep cavitation at the tip of the incipient shear zone (fig.9C).

The absence of strain localisation in pure olivine aggregates may be caused by the fact that strong CPx clasts as stress raisers are absent and creep cavitation may be homogeneous. Furthermore, a different degree of strain localisation, i.e. a wide shear zone instead of a narrow shear zone, is expected when there are more weakening areas, i.e., more olivine/CPx interfaces (finer-grained CPx 
produces more cavitation sites giving rise to a larger volume of weaker material and thus a wider zone).

This process provides a consistent approach to answer for strain localisation during olivine diffusion creep, with crucial implications for the lithosphere dynamics. For instance, recent quantifications of silicon diffusion in olivine (Fei et al., 2016) have predicted grain-boundary diffusion creep (coble creep) to be dominant - at the expense of dislocation creep - in the whole uppermost mantle. Moreover, numerical models of upper mantle convections have shown that strain localisation induced by grain size reduction during olivine diffusion creep have a great potential in promoting plate boundaries, which is a sine qua non condition for Plate Tectonics to originate (Bercovici and Ricard, 2014). We stress nevertheless that the nature of phase nucleation during diffusion creep remains an open question, particularly for mono-phase aggregates. The processes controlling grain size equilibrium within the diffusion creep field also remain very elusive. Defining an equilibrium grain size as a function of deformation parameters is indeed critical to quantify strain localisation in the lithospheric mantle, and hence, to better constrain its implications for the lithosphere dynamics.

\section{Conclusion}

In this study, we performed Griggs-type deformation experiments on pure olivine and composite (olivine + diopside) aggregates with $0.1-0.2 \mathrm{wt} \% \mathrm{H}_{2} \mathrm{O}$ at $900^{\circ} \mathrm{C}$ and $1.2 \mathrm{GPa}$. Starting with a mean grain size of $2 \mu \mathrm{m}$ for olivine, we explored how diffusion creep may be important for grain size reduction and strain localisation in the wet uppermost mantle. While we document olivine grain size reduction and a substantial weakening for all sample types, we develop typical ductile shear zones for two-phase samples. Strain localisation is coeval with complete phase mixing of olivine and CPx in very fine-grained layers that extend from CPx porphyroclasts. The phase mixture is also found as mantling CPx tails with strong LPO, as well as in cracks of large CPx with fluid inclusions. For 
olivine aggregates, we further document (1) some cracks containing new grains, and (2) absent or very weak LPO (B-type fabric) despite substantial finite strain.

While phase mixing is inferred to form by nucleation of two-phase aggregates at olivine/pyroxene interfaces, both, olivine grain size reduction and strain localisation are proposed to arise from creep cavitation induced by grain boundary sliding and subsequent fluid-assisted nucleation. These findings provide a key source for strain localisation in the uppermost mantle, including at the scale of the lithosphere. We therefore emphasize creep cavitation and diffusion creep to be considered in future studies investigating on the consequences of strain localisation for the lithosphere.

\section{Acknowledgments}

We thank Matej Pec and Sina Marti for their help in performing experiments and acquiring SEM images. Discussions with David Kohlstedt, Mark Zimmerman, Renée Heilbronner and Nicole Le Breton have greatly helped to improve the content of this manuscript. We also thank John P. Platt and an anonymous reviewer for their constructive comments, which have improved the manuscript. This study has been funded by the ETH Zürich (ETH fellowship application FEL01 09-3), ERC 
RHEOLITH (grant 290864) and Labex Voltaire (ANR-10-LABX-100-01). Support of the Kohlstedt lab and Charfac/Nanocenter of UMN for TEM analyses is gratefully acknowledged.

\section{Bibliography}

Austin, N. J., and Evans, B. (2007) Paleowattmeters: A scaling relation for dynamically recrystallized grain size. Geology 35(4): 343-346, doi: 10.1130/G23244A.1.

Bell, D. R., Rossman, G. R., Maidener, J., Endisch D., and Rauch, F. (2003) Hydroxide in olivine: a quantitative determination of the absolute amount and calibration of the IR spectrum. J. Geophys. Res. 108(B2): 2105, doi: 10.1029/2001JB000679.

Bercovici, D., and Ricard, Y. (2012) Mechanisms for the generation of plate tectonics by two-phase graindamage and pinning. Phys. Earth Planet. Int. 202-203: 27-55, doi: 10.1016/j.pepi.2012.05.003.

Bercovici, D., and Ricard, Y. (2014) Plate tectonics, damage and inheritance. Nature 508: 513-516, doi: 10.1038/nature13072.

Bons, P. D. and Den Brok B. (2000) Crystallographic preferred orientation development by dissolutionprecipitation creep. J. Struct. Geol. 22: 1713-1722, doi: 10.1016/S0191-8141(00)00075-4.

Bromiley, G. D., Keppler, H., McCammon, C., Bromiley, F. A, and Jacobsen, S. D. (2004) Hydrogen solubility and speciation in natural, gem-quality chromian diopside. American mineralogist 89: 941-949, doi: 10.2138/am-2004-0703.

Bunge, H. (1982) Texture analysis in materials Science: mathematical models. Butterworths, London, 593 pp.

Bürgman, R., and Dresen, G. (2008) Rheology of the Lower Crust and Upper Mantle: Evidence from Rock Mechanics, Geodesy, and Field Observations. Annu. Rev. Earth Planet. Sci. 36: 531-67, doi: 10.1146/annurev.earth.36.031207.124326.

Burov, E. B., and Watts, A. B. (2006) The long-term strength of continenal lithosphere: "Jelly sandwich" or “crème brûlée”. GSA today 16(1): 4-10, doi: 10.1130/1052-5173.

Chen, S., Hiraga, T., and Kohlstedt, D. L. (2006) Water weakening of dislocation creep in the dislocation creep regime. J. Geophys. Res. 111: B08203, doi: 10.1029/2005JB003885.

de Bresser, J. H. P., Ter Heege, J. H., and Spiers, C. J. (2001) Grain size reduction by dynamic recrystallization: can it result in major rheological weakening? Int. J. Earth Sci. 90: 28-45, doi: 10.1007/s005310000149. 
de Ronde, A. A., Stünitz, H., Tullis, J., and Heilbronner, R. (2005) Reaction-induced weakening of plagioclaseolivine composites. Tectonophysics 409: 85-106, doi: 10.1016/j.tecto.2005.08.008.

Dijkstra, A. H., Drury, M. R., and Frijkoff, M. (2002) Microstructures and lattice fabrics in the Hilti mantle section (Oman Ophiolite): Evidence for shear localization and melt weakening in the crust-mantle transition zone? J. Geophys. Res. 107(B11): 2270, doi: 10.1029/2001JB000458.

Dimanov, A., Rybacky, E., Wirth, R., and Dresen, G. (2007) Creep and strain-dependent microstructures of synthetic anorthite-diopside aggregates. J. Struct. Geol. 29: 1049-1069, doi: 10.1016/j.jsg.2007.02.010.

Drury, M. R., Vissers, R. L. M., Van der Wal, D., and Hoogerduijn Strating, E. H. (1991) Shear Localisation in Upper Mantle Peridotites. PAGEOPH 137(4): 439-460, doi: 10.1007/BF00879044.

Drury, M. R., Ave'Lallemant, H. G., Pennock, G. M., and Palasse, L. N. (2011) Crystal preferred orientation in peridotite ultramylonites deformed by grain size sensitive creep, Etang de Lers, Pyrenees, France. $J$. Struct. Geol. 33: 1776-1789, doi: 10.1016/j.jsg.2011.10.002.

Farla, J. M., Karato, S.-I, and Cai, Z. (2013) Role of orthopyroxene in rheological weakening of the lithosphere via dynamic recrystallization. PNAS 110(41): 16355-16360, doi: 10.1073/pnas.1218335110.

Fei, H., Koizumi, S., Sakamoto, N., Hashiguchi, M., Yurimoto, H., Marquardt, K., Miyajima, N., Yamazaki, D., and Katsura, T. (2016) New constraints on upper mantle creep mechanism inferred from silicon grainboundary diffusion rates. Earth Planet. Sci. Lett. 433: 350-359, doi: 10.1016/j.epsl.2015.11.014.

Fliervoet, T., F., Drury, M. R., and Chopra, P. N. (1999) Crystallographic preferred orientations and misorientations in some olivine rocks deformed by diffusion or dislocation creep. Tectonophysics 303: 127, doi: 10.1016/S0040-1951(98)00250-9.

Fusseis, F., Regenauer-Lieb, K., Liu, J., Hough, R.M., and De Carlo, F. (2009) Creep cavitation can establish a dynamic granular fluid pump in ductile shear zones. Nature 459: 974-977, doi: 10.1038/nature08051.

Hansen, L. N., Zimmerman, M. E., and Kohlstedt, D. L. (2011) Grain boundary sliding in San Carlos olivine: Flow law parameters and crystallographic-preferred orientation. J. Geophys. Res. 116: B08201, doi: 10.1029/2011JB008220.

Hansen, L. N., Zimmerman, M. E., and Kohlstedt, D. L. (2012) The influence of microstructure on deformation of olivine in the grain-boundary sliding regime. J. Geophys. Res. 117: B09201, doi: 10.1029/2012JB009305. 
Hansen, L. N., Zhao, Y.-H., Zimmerman, M. E., and Kohlstedt, D. L. (2014) Protracted fabric evolution in olivine: Implications for the relationship among strain, crystallographic, and seismic anisotropy. Earth Planet. Sci. Lett. 387: 157-158, doi: 10.1016/j.epsl.2013.11.009.

Herwegh, M., Linckens, J., Ebert, A., Berger, A., and Brodhag, S. H. (2011) The role of second phases for controlling microstructural evolution in polymineralic rocks: A review. J. Struct. Geol. 33: 1728-1750, doi: 10.1016/j.jsg.2011.08.011.

Hiraga, T., Tachibana, C., Ohashi, N., and Sano, S. (2010) Grain growth systematics for forsterite \pm enstatite aggregates: Effect of lithology on grain size in the upper mantle. Earth Planet. Sci. Lett. 291: 10-20, doi: 10.1016/j.epsl.2009.12.026.

Hiraga, T., Miyazaki, T., Yoshida, H., and Zimmerman, M. E. (2013) Comparison of microstructures in superplastically deformed synthetic materials and natural mylonites: Mineral aggregation via grain boundary sliding. Geology 41(9): 959-962, doi: 10.1130/G34407.1.

Hirth, G., and Kohlstedt, D.L. (2003) Rheology of the Upper Mantle and the Mantle Wedge: A View from the Experimentalists. Geophysical monograph 138: 83-105, doi: 10.1029/138GM06.

Hirth, G., and Tullis, J. (1992) Dislocation creep regimes in quartz aggregates. J. Sruct. Geol. 14(2): 145-159, doi: 10.1016/0191-8141(92)90053-Y.

Jenkins, D. M. (1983) Stability and Composition Relations of Calcic Amphiboles in Ultramafic Rocks. Contrib Mineral Petrol 83: 375-384, doi: 10.1007/BF00371206.

Jung, H., and Karato, S.-I. (2001) Water-Induced Fabric Transitions in Olivine. Science 293: 1460-1463, doi: 10.1126/science.1062235.

Karato, S.-I., Paterson, M. S., and Fitz Gerald, J. D. (1986) Rheology of Synthetic Olivine Aggregates: Influence of Grain Size and Water. J. Geophy. Res. 91(B8): 8151-8176, doi: 10.1029/JB091iB08p08151.

Kassner, M. E., and Hayes, T. A. (2003) Creep cavitation in metals. Int. J. Plast. 19: 1715-1748, doi: 10.1016/S0749-6419(02)00111-0.

Kilian, R., Heilbronner R., and Stünitz, H. (2011) Quartz grain size reduction in a granitoid rock and the transition from dislocation to diffusion creep. J. Struct. Geol. 33: 1265-1284, doi: 10.1016/j.jsg.2011.05.004.

Kohlstedt, D. L., Keppler, H., and Rubie, D. C. (1996) Solubility of water in the $\alpha, \beta$ and $\gamma$ phases of (Mg, Fe) ${ }_{2} \mathrm{SiO}_{4}$. Contrib. Mineral. Petrol. 123: 345-357, doi: 10.1007/s004100050161. 
Kohlstedt, D. L., Evans, B., and Mackwell, S. J. (1995) Strength of the lithosphere: Constraints imposed by laboratory experiments. J. Geophy. Res. 100(B9): 17,587-17,602, doi: 10.1029/95JB01460.

Langdon, T. G. (2006) Grain boundary sliding revisited: Development in sliding over four decades. J. Mater. Sci. 41: 597-609, doi: 10.1007/s10853-006-6476-0.

Linkens, J., Bruijn, R. H. C., and Skemer, P. (2014) Dynamic recrystallization and phase mixing in experimentally deformed peridotite. Earth Planet. Sci. Lett. 388: 134-142, doi: 10.1016/j.epsl.2013.11.037.

Mainprice, D., Backmann, F., Hielscher, R., and Schaeben, H. (2015) Descriptive tools for the analysis of texture projects with large datasets using MTEX: strength, symmetry and components. Geological Society, London, Special Publications 409: 251-271, doi: 10.1144/SP409.8.

Miyazaki, T., Sueyoshi, K., and Hiraga, T. (2013) Olivine crystals align during diffusion creep of Earth's upper mantle. Nature 502: 321-326, doi: 10.1038/nature12570.

Newman, J., Lamb, W.M., Drury, M.R., and Vissers, R.L.M. (1999) Deformation processes in a peridotite shear zone: reaction-softening by an $\mathrm{H} 2 \mathrm{O}$-deficient, continuous net transfer reaction. Tectonophysics 303: 193-202, doi: 10.1016/S0040-1951(98)00259-5.

Platt, J. P. (2015) Rheology of two-phase systems: A microphysical and observational approach. J. Struct. Geol. 77: 213-227, doi: 10.1016/j.jsg.2015.05.003.

Platt, J. P. and Behr, W. M. (2011) Grainsize evolution in ductile shear zones: Implications for strain localization and the strength of the lithosphere. J. Struct. Geol. 33: 537-550. doi: 10.1016/j.jsg.2011.01.018.

Ramsay, J. G. (1980) Shear zone geometry: a review. J. Struct. Geol. 2(1-2): 83-99, doi: 10.1016/01918141(80)900038-3.

Rutter, E. H., and Brodie, K. H. (1988) The role of tectonic grain size reduction in the rheological stratification of the lithosphere. Geologische Rundschau 277(1): 295-308, doi: 10.1007/BF01848691.

Skemer, P., Katayama, I., Jiang, Z., and Karato, S.-I. (2005) The misorientation index: Development of a new method for calculating the strength of lattice-preferred orientation. Tectonophysics 411: 157-167, doi: 10.1016/j.tecto.2005.08.023.

Stünitz, H., and Fitz Gerald J. D. (1993) Deformation of granitoïds at low metamorphic grade. II: Granular flow in albite-rich mylonites. Tectonophysics 221(3-4): 299-324, doi: 10.1016/0040-1951(93)90164-4. 
Sundberg, M., and Cooper, R. F. (2008) Crystallographic preferred orientation produced by diffusional creep of harzburgite: Effects of chemical interactions among phases during plastic flow. J. Geoph. Res. 113: B12208, doi: 10.1029/2008JB005618.

Van der Wal, D., Chopra, P., Drury, M., and Fitz Gerald, J. (1993) Relationships between dynamically recrystallized grain size and deformation conditions in experimentally deformed olivine rocks. Geophy. Res. Lett. 20(14): 1479-1482, doi: 10.1029/93GL01382.

Warren, J. M., and Hirth, G. (2006) Grain size sensitive deformation mechanisms in naturally deformed peridotites. Earth Planet. Sci. Lett. 248(1-2): 438-450, doi: 10.1016/j.epsl.2006.06.006.

Zhao, Y.-H., Ginsberg, S. B., and Kohlstedt, D. L. (2004) Solubility of hydrogen in olivine: dependence on temperature and iron content. Contrib. Mineral. Geol. 147: 155-161, doi: 10.1007/s00410-003-0524-4.

\section{Table and figures captions}

Table 1 | Sample water content - Post-experiment water content of the olivine matrix and single crystals (in wt. ppm of $\mathrm{H}_{2} \mathrm{O}$ ) in the hot-pressed, peak stress, pure olivine and composites samples. The measurements have been performed using ion probe at the CRPG (Nancy, France) on gold-coated thin section (see text for analytical conditions). The terms "amph." and "SZ" refer to a measurement taken by an amphibole grain or within the high-strain shear zone, respectively.

Figure 1 | Sample assembly, strain-stress curves and microstructures. A) Sample assembly in the Griggs-type apparatus. $\mathrm{WC}=$ Tungsten carbide $\mathrm{Pt}=$ Platinum; $\sigma_{1}=$ deformation piston; $\sigma_{3}=$ confining piston. B) Differential stress (MPa) versus shear strain $(\gamma)$ that shows the mechanical behaviour of a pure olivine sample (green), two composite samples with $30 \mathrm{wt} \%$ of fine-grained $(5-20 \mu \mathrm{m}) \mathrm{CPx}$ (light blue), and two composite samples, including a "peak-stress" experiment, with 30 wt.\% of coarse-grained (40-125 $\mu \mathrm{m}) \mathrm{CPx}$ (purple). For all experiments, the olivine grain size is between 1 and $10 \mu \mathrm{m}$, and the temperature, confining pressure and bulk strain rate are set to $900^{\circ} \mathrm{C}, 1.2 \mathrm{GPa}$, and $\sim 3.10^{-5} \mathrm{~s}^{-1}$, respectively. C) SEM image (BackScatter Electron (BSE) image) of the pure olivine sample. The analytical conditions are described in the text. D) BSE image of the composite sample with coarse-grained CPx. Strain localisation occurred near the bottom side within a shear zone of $\sim 50 \mu \mathrm{m}$ width. E) BSE image of one two-phase sample with fine-grained CPx. The second experiment shows the same microstructure. Strain localised within a shear zone of $\sim 150 \mu \mathrm{m}$ width 
where shear bands have been developed. For both sample types (with fine vs. coarse CPx), we also give an estimation of the finite strain $(\gamma)$ involved at the right of each picture based on the angle $(\theta)$ between the long axis of CPx (dotted lines) and shear plane (piston side). $\gamma=2 / \tan 2 \theta$ (Ramsay, 1980). From F to H) BSE images of the bi-phase deformation product (mixture) that extends from starting CPx. The mixture of CPx + $\mathrm{Ol}$ also rims pure $\mathrm{CPx}$ aggregates.

Figure 2 | Phase mixture and cracking. From A to C) TEM images (bright field) through Focused Ion Beam (FIB) section of a mixture layer (A) and adjacent olivine matrix (B) in the shear zone of the composite sample with coarse-grained CPx. In the matrix, a few dislocations (B) and some cracks with new olivine grain (C) have been observed. D) BSE image of cracks filled by two-phase mixture at the rim of large pyroxene grains. These cracks only develop in the direction of maximum normal stress. E and F) Observations at the polarized optical microscope and SEM (BSE) image of fluid inclusions at the tip of CPx cracks. Ol= olivine; $\mathrm{CPx}=$ clinopyroxene.

Figure 3 | Composition of the starting material and deformation product. A) Element map (microprobe) of the magnesium distribution in the shear zone of the sample with coarse-grained CPx. The location is shown in figure 1D. The color scale refers to point counting of elements. From B to D) Microprobe analyses that document the Magnesium $(\mathrm{Mg})$, Calcium $(\mathrm{Ca})$ and Iron $(\mathrm{Fe})$ contents (per unit of structural formulae normalised for 4 cations) of olivine (green squares), CPx (light blue squares) and mixture (red squares) in the same area. We also show spot analyses of the starting material, including olivine and diopside (black squares). $\mathrm{Mg} \#=\mathrm{Mg} /(\mathrm{Mg}+\mathrm{Fe})$. We only give an overall composition of the mixture because its grain size $(\sim 0.1 \mu \mathrm{m})$ is one order of magnitude below the spot size $(\sim 1 \mu \mathrm{m})$ of the microprobe beam. Thus, several grains of the mixture are measured in one measurement. The mixture composition extends from the changed composition of olivine and CPx grains, indicating that (1) olivine and CPx compose the mixture, and (2) starting olivine and CPx grains equilibrated at $900^{\circ} \mathrm{C}$ and $1.2 \mathrm{GPa}$ (best seen in D). E) Chemical analyses of olivine and pyroxene grains in the phase mixture using EDX at the TEM. The graph axes refer to the Mg\# and 
$\mathrm{Si} / \mathrm{Mg}$ ratio based on point counting. While the element contents are consistent with olivine and diopside as composing the mixture, they show some variations that we attribute to local equilibrium (see text).

Figure 4 | Olivine Lattice Preferred Orientation (LPO). From top to bottom, we document the olivine LPO after hot-pressing $(\gamma=0)$, at peak stress conditions $(\gamma=1)$, after deformation of the pure olivine sample $(\gamma=2.5)$, and within the shear zones of the two-phase samples with fine-grained $\mathrm{CPx}(\gamma>5)$ and coarse-grained CPx $(\gamma>10)$. The LPOs are shown in lower-hemisphere pole figures of the three reference axes for orthorhombic olivine ([100], [010] and [001]) with respect to the shear direction (white dot) and shear plane (horizontal solid line). The contours and grey shading highlight multiples of uniform distribution. These LPO includes one point per grain acquired manually (the map-based LPOs are available in supplementary figure 2). $\mathrm{N}=$ number of data; $\mathrm{J}=$ texture index (Bunge, 1982); $\mathrm{M}=$ misorientation index (Skemer et al., 2005).

Figure 5 | Olivine grain size distribution. Histograms of grain size diameter $(\mu \mathrm{m})$ versus area fraction (\%) for each category of olivine grain size. The grain sizes have been calculated based on EBSD maps shown in figure 6 and using area-equivalent diameter. The threshold angle of misorientation to define grain boundaries was $10^{\circ}$. The step size was $0.3 \mu \mathrm{m}$, except for the sample with $\gamma>10$ where we used a step size of $0.2 \mu \mathrm{m}$. From top to bottom, we show the grain size distribution of a hot-pressed sample (which includes 30 wt. $\%$ of fine-grained CPx), a sample quenched at peak stress conditions (which includes $30 \mathrm{wt} . \%$ of coarse-grained CPx), and the final grain size distribution for the pure olivine sample, two-phase sample with fine-grained CPx and two-phase sample with coarse-grained CPx. The data for deformed two-phase samples have been acquired within their respective shear zones. Both the mean (red line) and mode (orange line) show a grain size reduction (black arrow) from the peak stress onward. $\mathrm{N}=$ number of olivine grains.

Figure 6 | Spatial distribution and pyroxene LPOs. A) EBSD maps combined with inverse pole figures (IPF; bottom left) of olivine LPO within the pure olivine sample $\left(\mathrm{A}_{1}\right)$, the shear zone of one two-phase sample with fine-grained $\operatorname{CPx}\left(\mathrm{A}_{2}\right)$, and the one with coarse-grained $\mathrm{CPx}\left(\mathrm{A}_{3}\right)$. The color coding refers to the angle (between 0 and $90^{\circ}$ ) of each axis with respect to the shear direction (X). The step size is $0.3 \mu \mathrm{m}$ for all maps, except for the sample with $\gamma>10\left(\mathrm{~A}_{3}\right)$ where we used a step size of $0.2 \mu \mathrm{m}$. We give the maximum finite strain $(\gamma)$ for indication. Grain boundaries are defined considering misorientation angles higher than $10^{\circ}$. The black 
areas are CPx grains and non-indexed points. B) Map-related distribution of olivine grain size for the pure olivine $\left(B_{1}\right)$ and composite samples with fine- $\left(B_{2}\right)$ and coarse-grained $\left(B_{3}\right) C P x$. We considered three categories of grain size: below $1 \mu \mathrm{m}$ (red), between 1 and $3 \mu \mathrm{m}$ (green), and above $3 \mu \mathrm{m}$ (grey). C and D) LPO (C) and EBSD map (D) combined with IPF of pyroxene grains in the shear zone of a sample with finegrained CPx. The location is shown is figure $6 \mathrm{~A}_{2}$. $\mathbf{E}$ and F) LPO (E) and EBSD map (F) combined with IPF of pyroxene tails in the shear zone of a sample with coarse-grained CPx. LPOs are shown for the (100) plane, (010) plane and [001] axis of diopside with respect to the shear direction (white dot) and shear plane (horizontal solid line) considering one point per grain $(\mathrm{N}=$ number of grain). Contours and grey shading are multiples of uniform distribution. $\mathrm{J}=$ texture index; $\mathrm{M}=$ misorientation index. For coarse-grained $\mathrm{CPx}(\mathrm{F})$, we also show a second EBSD map with randomly attributed color for each grain, highlighting the grain size distribution in CPx tails.

Figure 7 | Mechanism of crack healing by phase mixture. A crack first opens in the direction of maximum normal stress $\left(\sigma_{1}\right)$, promoting pumping of the surrounding fluid from the grain boundary. The fluid solute (mixture) precipitates because of stress drop in the opening crack where a part of fluid is trapped (fluid inclusions).

Figure 8 | Deformation mechanism map (DMM) for wet olivine at $900^{\circ} \mathrm{C}$ and $1.2 \mathrm{GPa}$. DMM predicts the strain rate and dominant deformation mechanism, i.e., dislocation creep vs. diffusion creep, as a function of differential stress and mean grain size for olivine. On this DMM, we plot the deformation conditions (stress and grain size) at peak stress and after deformation $(\gamma=2.5)$ of the pure olivine sample (green squares), as well as conditions after deformation of the two-phase samples with fine- $(\gamma>5$; light blue square) and coarsegrained CPx $(\gamma>10$; purple square), including the mixtures. The DMM has been constructed after flow laws from Hirth and Kohlstedt (2003) using a water concentration of 1000 ppm and applying the correction for diffusion creep of Hansen et al. (2011). The olivine piezometer (yellow line) defines the stress-grain size relationships for dynamically recrystallized grains (Van der Wal et al., 1993). The dotted yellow line defines the minimum size of bulge for olivine (Platt and Behr, 2011). For the pure olivine sample, we highlight substantial weakening within the diffusion creep field and below both, the olivine piezometer and minimum size of bulge (black arrow). 


\section{Figure 9 | Model of fluid-assisted nucleation and strain localisation during diffusion creep. A)}

Nucleation induced by creep cavitation during plastic deformation of an olivine aggregate (green), including intra-crystalline deformation (diffusion creep) and grain boundary sliding (GBS). As a consequence of GBS, some cavities are formed and instantaneously filled by precipitation of new olivine grains (red). These new, randomly oriented grains then grow at the expense of the old ones while the olivine aggregate keeps deforming. B) Sketches that illustrate the formation of phase mixture at olivine (green)-pyroxene (light blue) interfaces because of GBS-related creep cavitation and dissolution-precipitation (solution transfer) during diffusion creep (modified after Kassner and Hayes, 2003). The olivine-pyroxene mixture (yellow) forms by (1) dissolution of the olivine and pyroxene components at stressed interfaces, i.e., normal to the maximum stress $\left(\sigma_{1}\right)$, and then (2) precipitation of the fluid solute in low-stress sites produced by GBS. C) Creep cavitation as a source for strain localisation. Because of stress concentrations (color scale) at pyroxene boundaries that stand at high angle to the direction of $\sigma_{1}$, creep cavitation and related nucleation are locally enhanced in the olivine matrix, which weakens and starts localising strain owing to grain size reduction. Due to shear stress concentrations at the tip of the shear zone, the shear plane propagates into the olivine matrix. While solution transfer produces the olivine-pyroxene mixture, the tails of pure $\mathrm{CPx}$ are produced by dynamic recrystallization. $\mathrm{CPx}=$ clinopyroxene. 
Figure 1
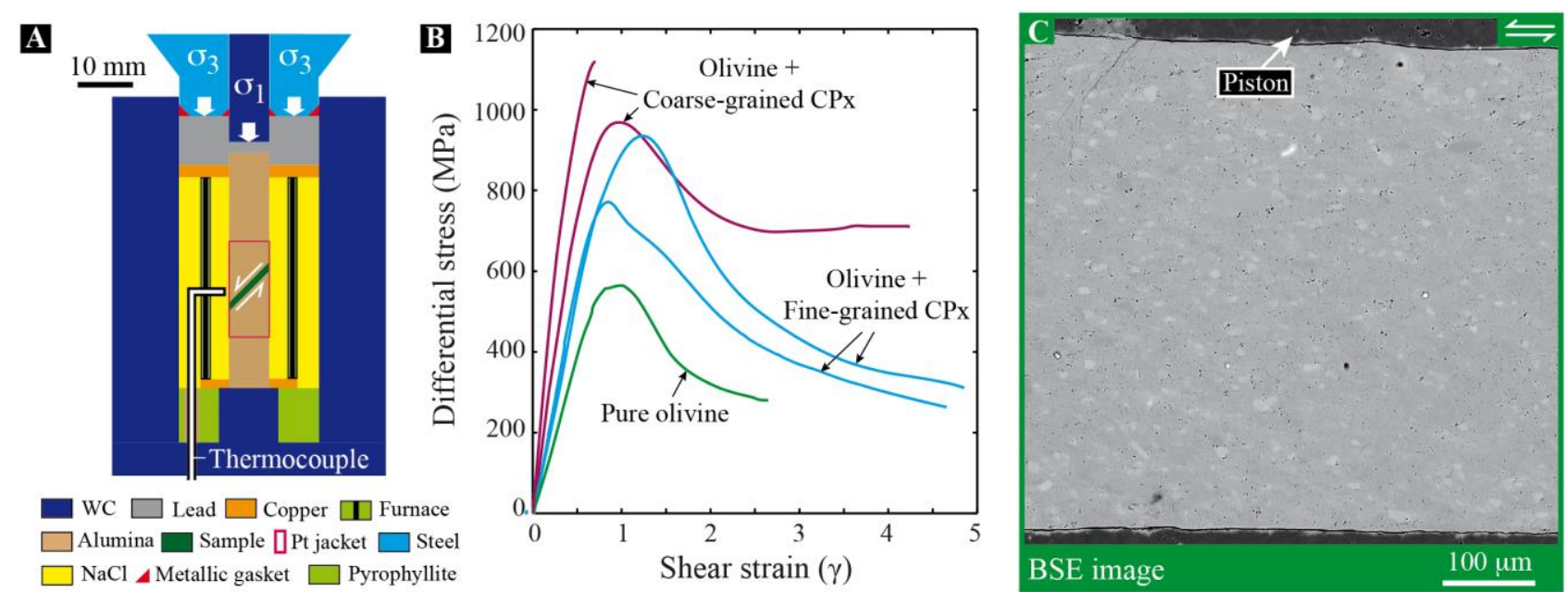

$\square$ wC $\square$ Lead $\square$ Copper $\square$ Furnace
$\square$ Alumina $\square$ Sample $\square$ Pt jacket $\square$ Stee
$\square$ NaCl 4 Metallic gasket $\square$ Pyrophyllite
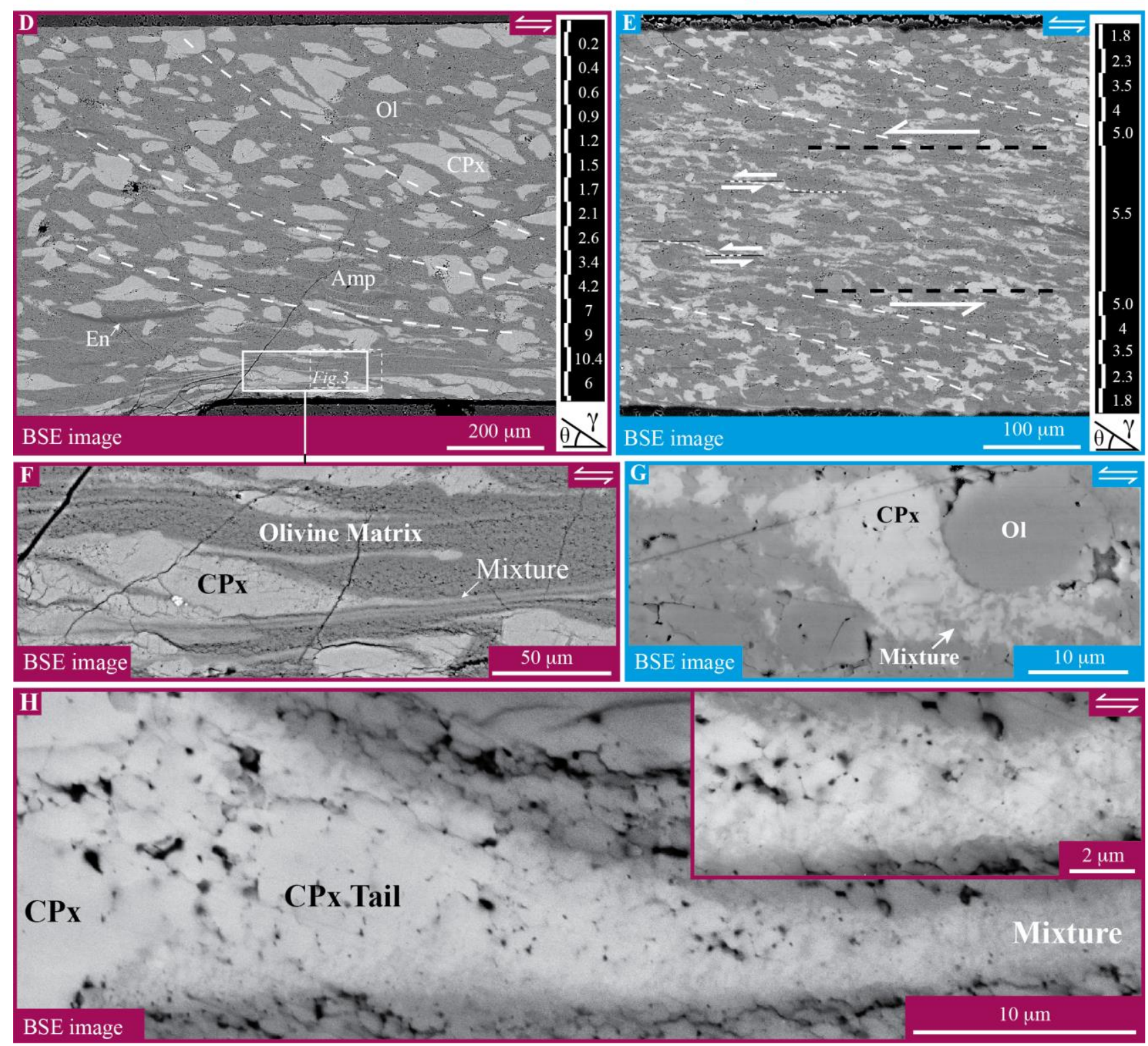
Figure 2
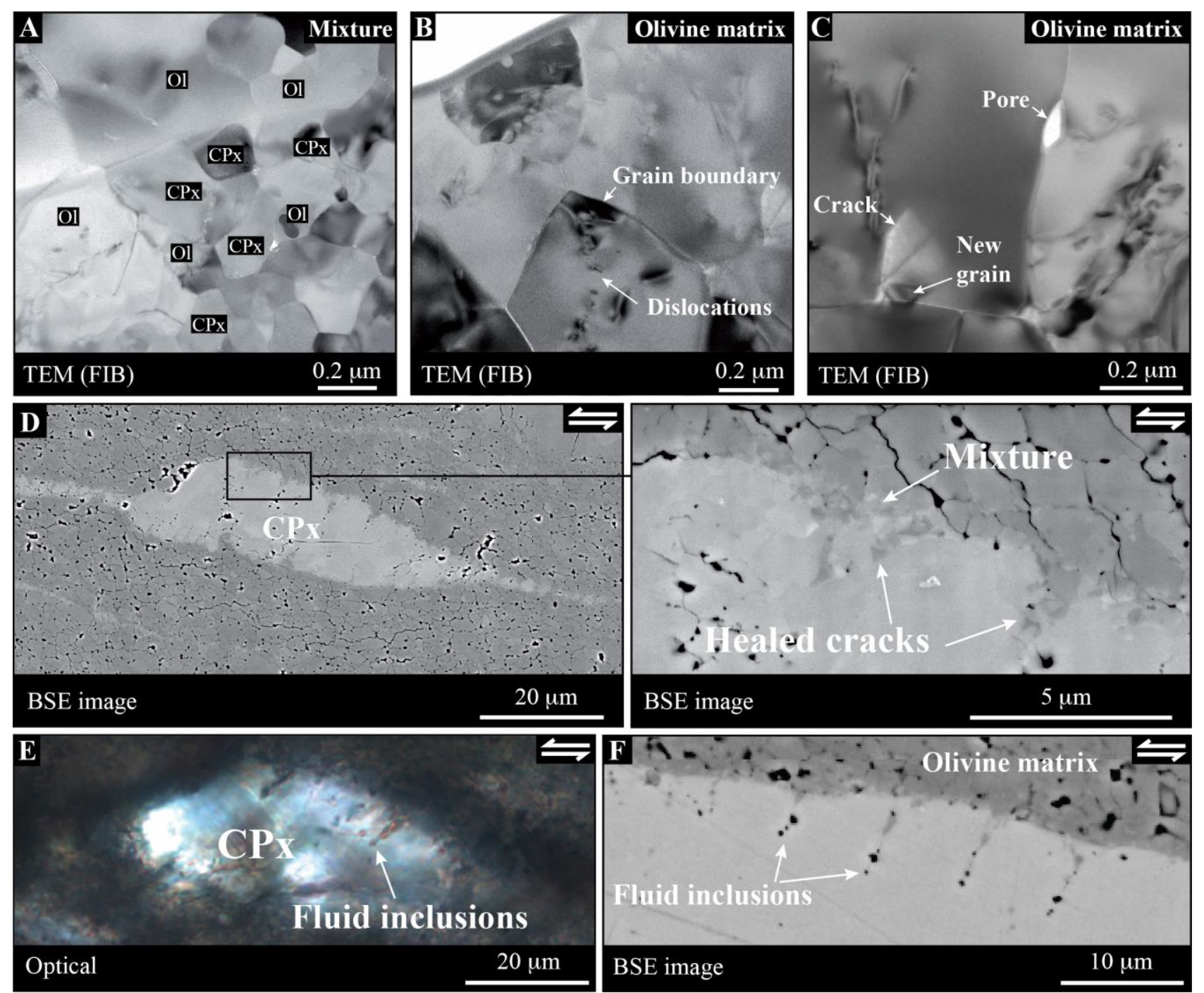
Figure 3
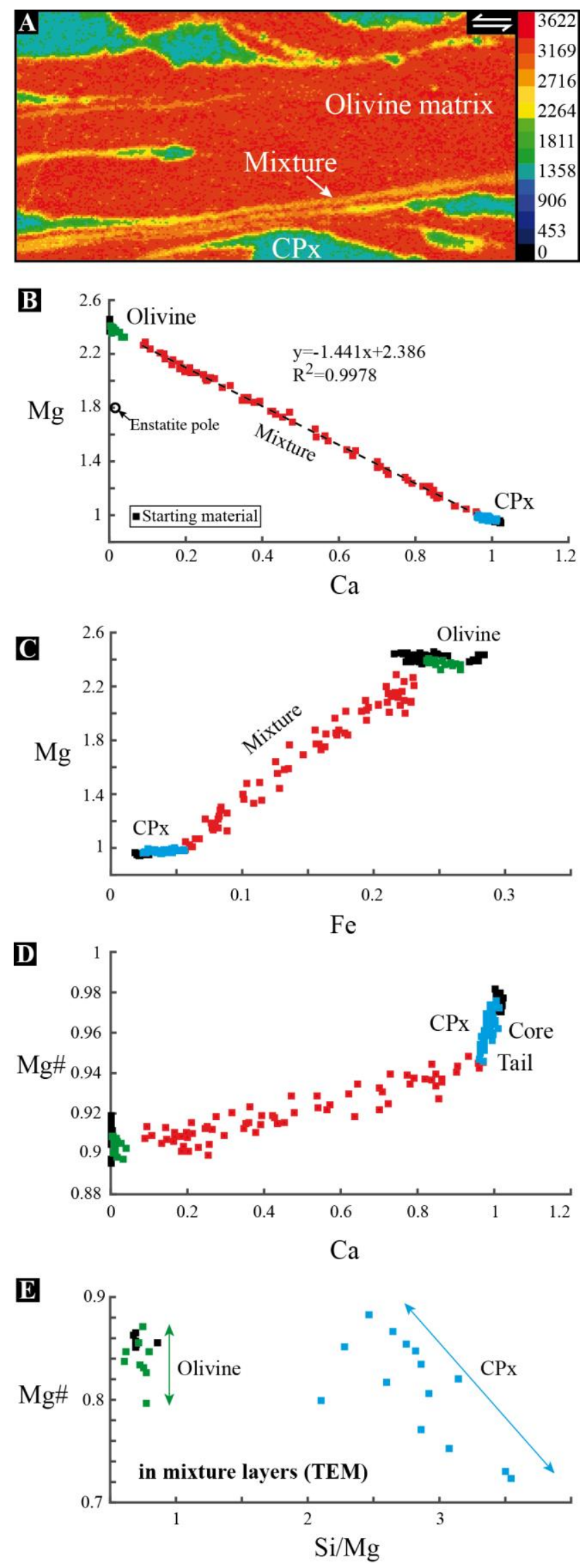
Figure 4
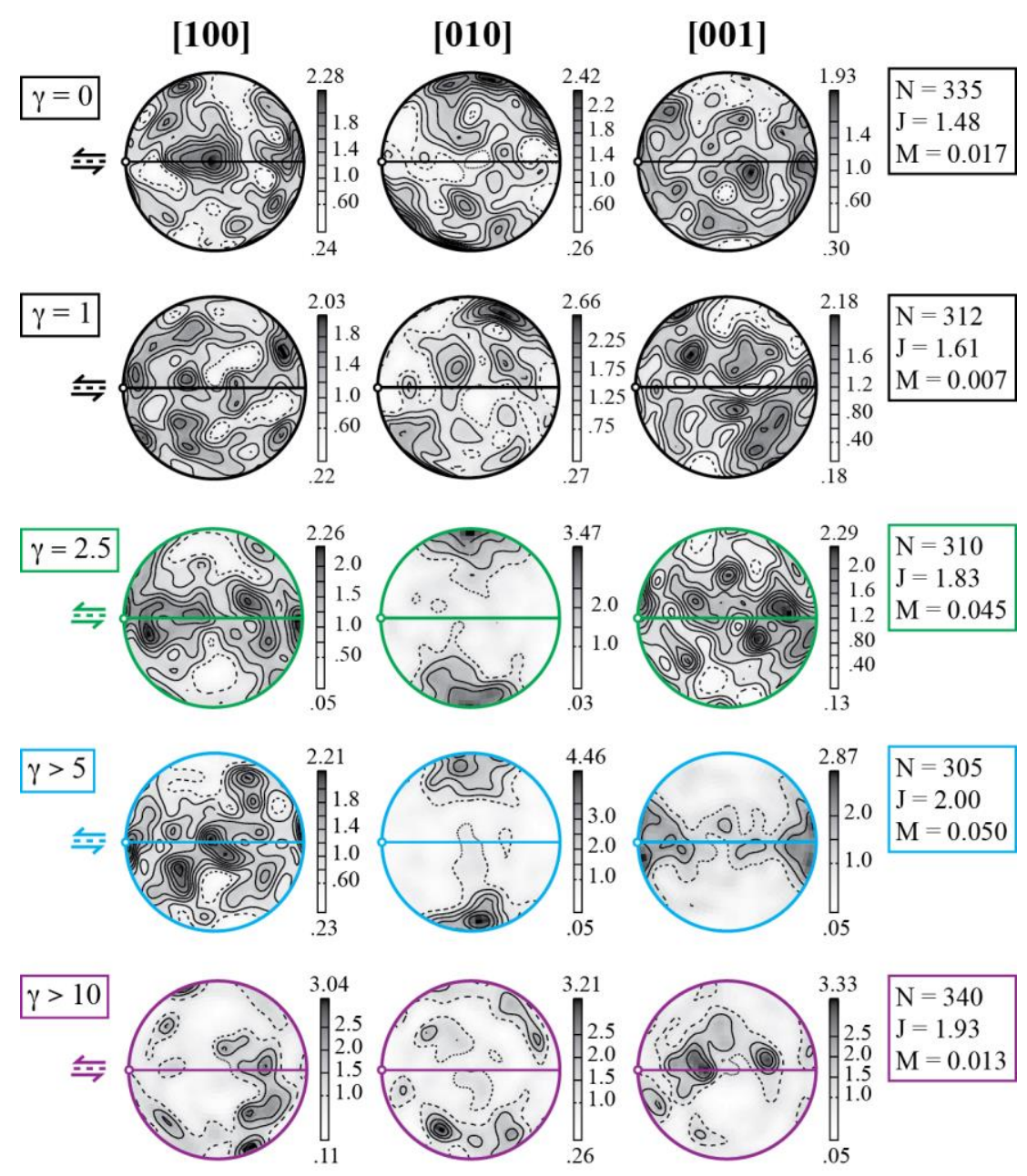
Figure 5
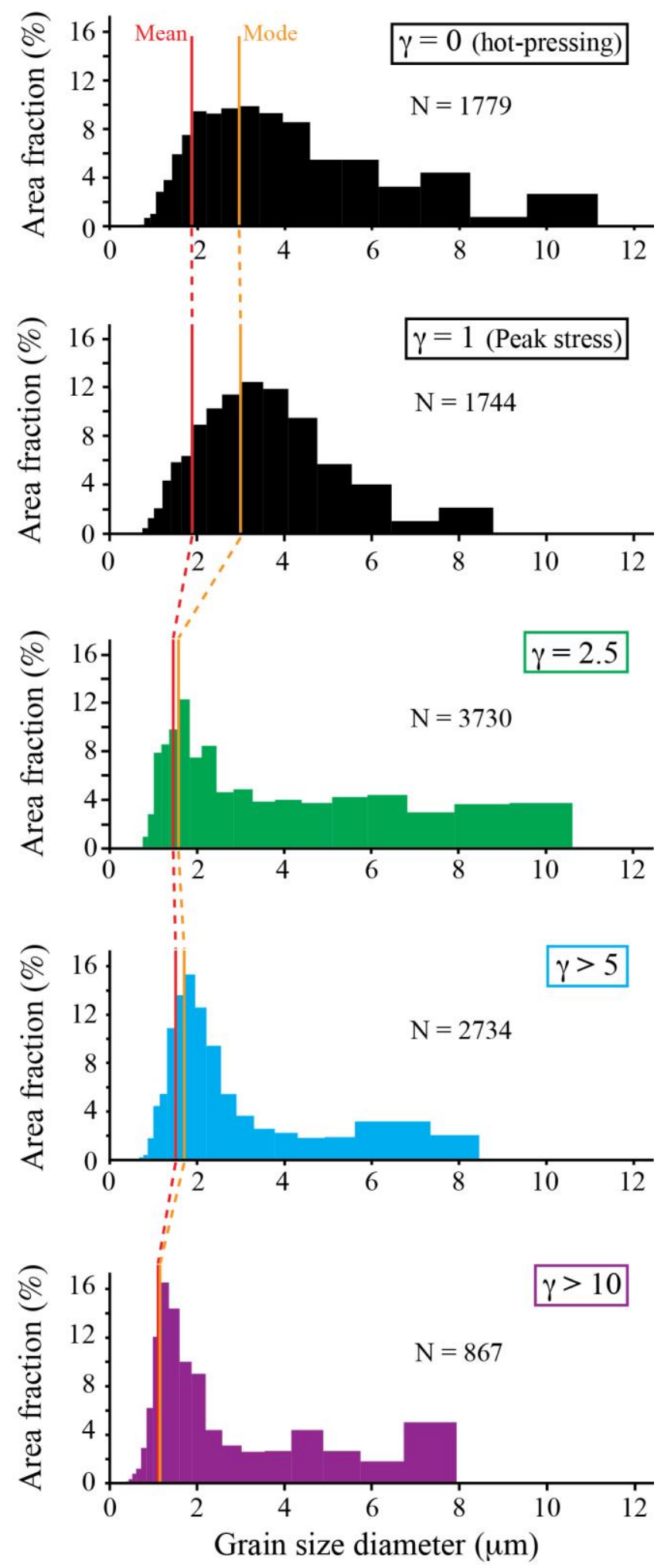
Figure 6
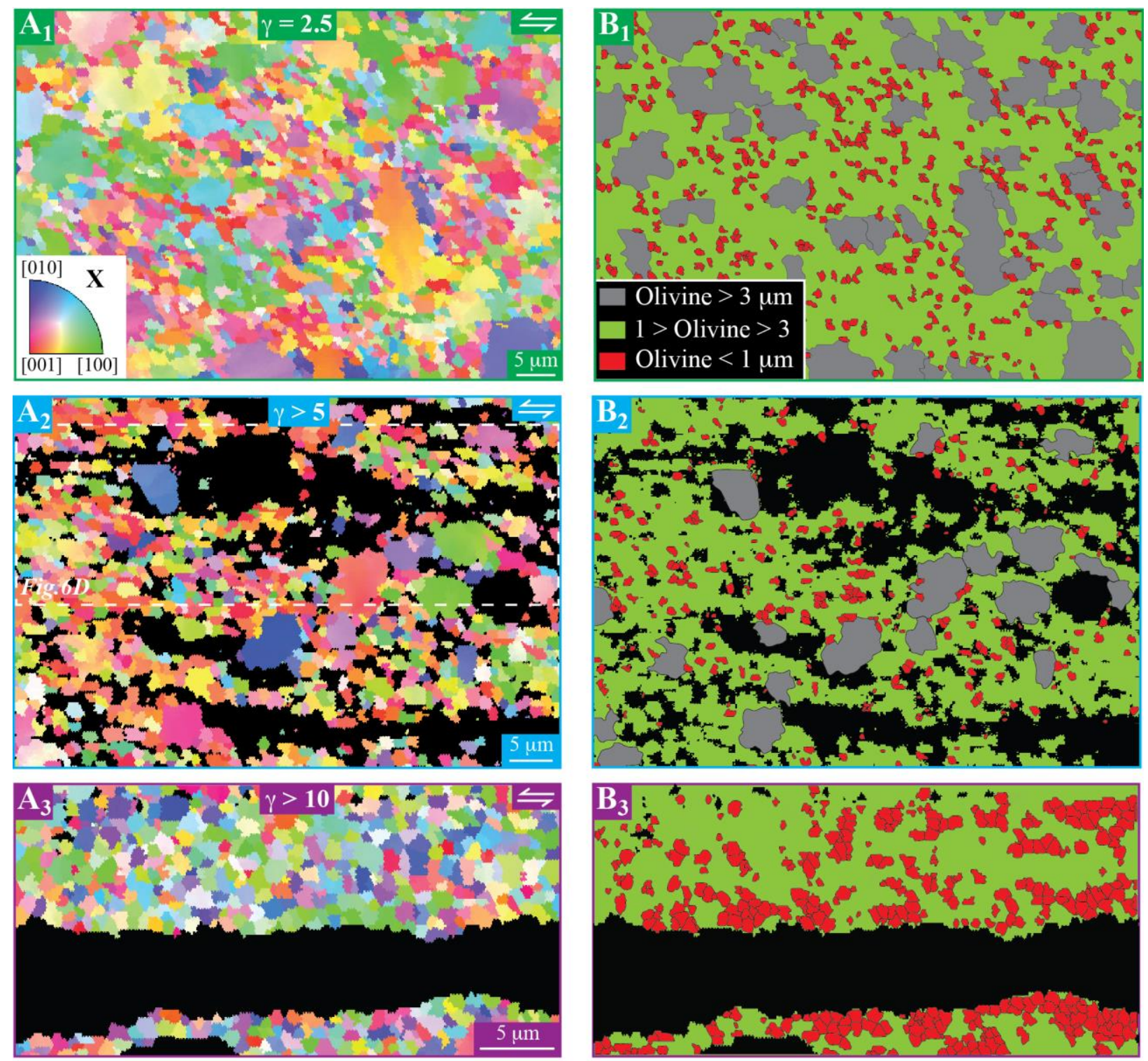

C

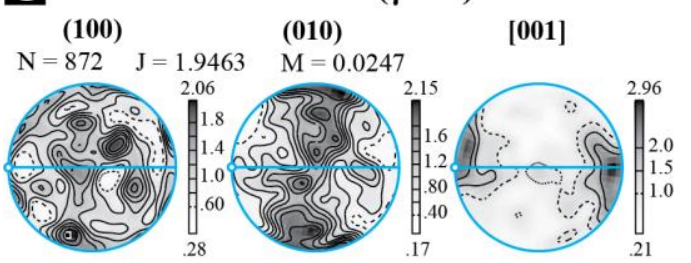

E Coarse CPx $(\gamma>10)$

$\mathrm{N}=103 \quad \mathrm{~J}=28.2817 \quad \mathrm{M}=0.4014$

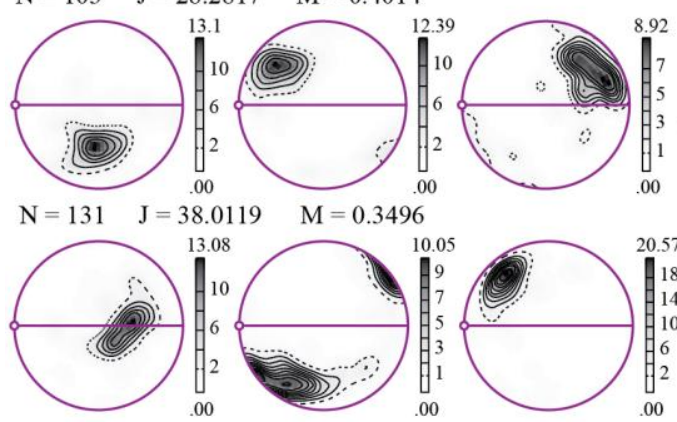

D Fine CPx $(\gamma>5)$
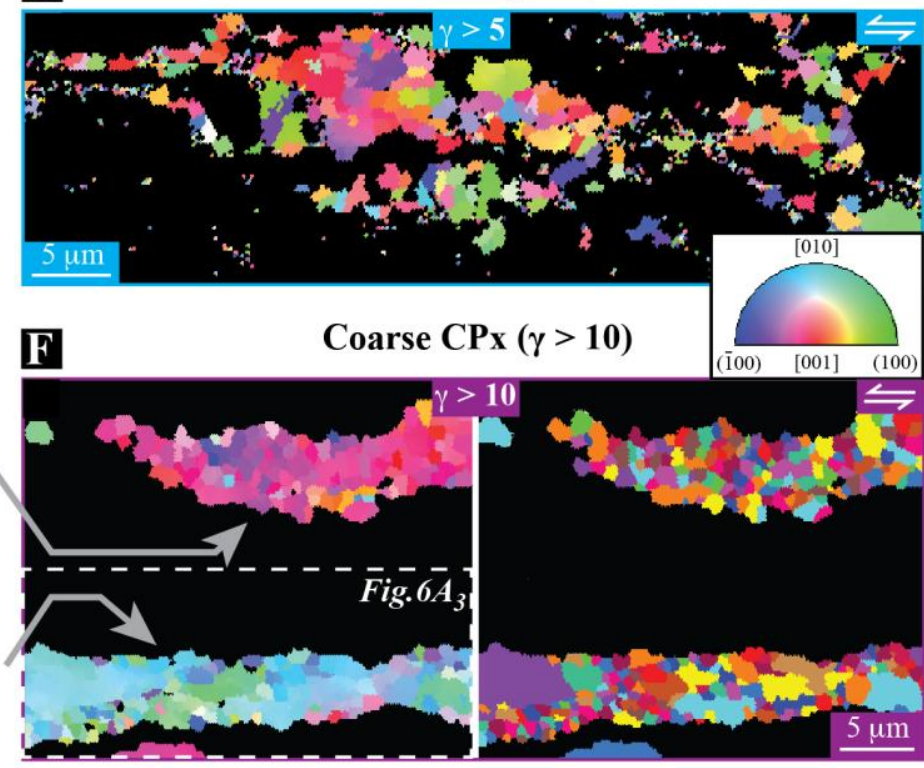
Figure 7
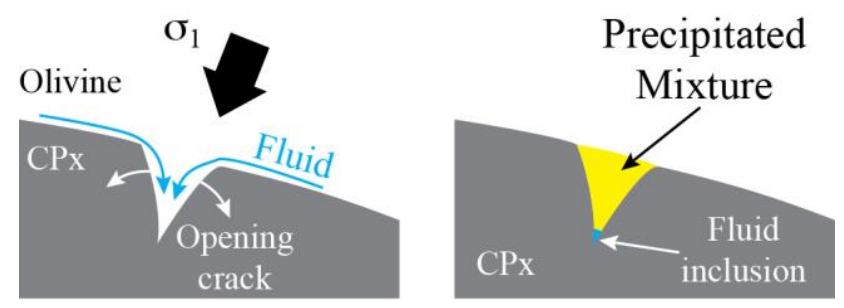
Figure 8

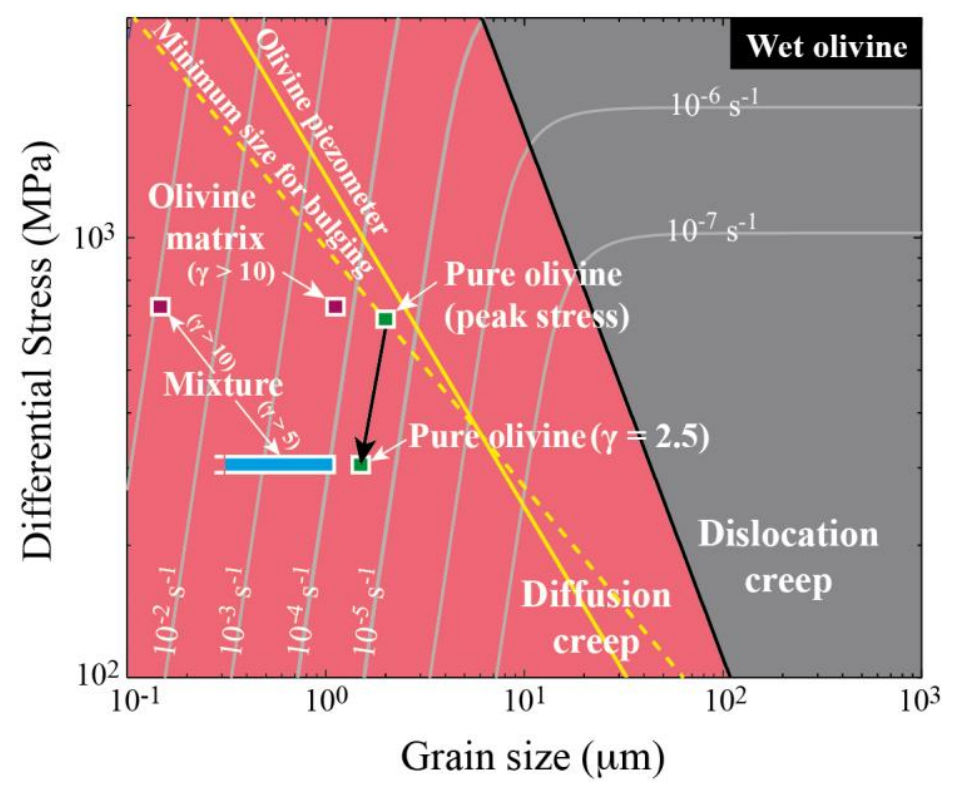


Figure 9
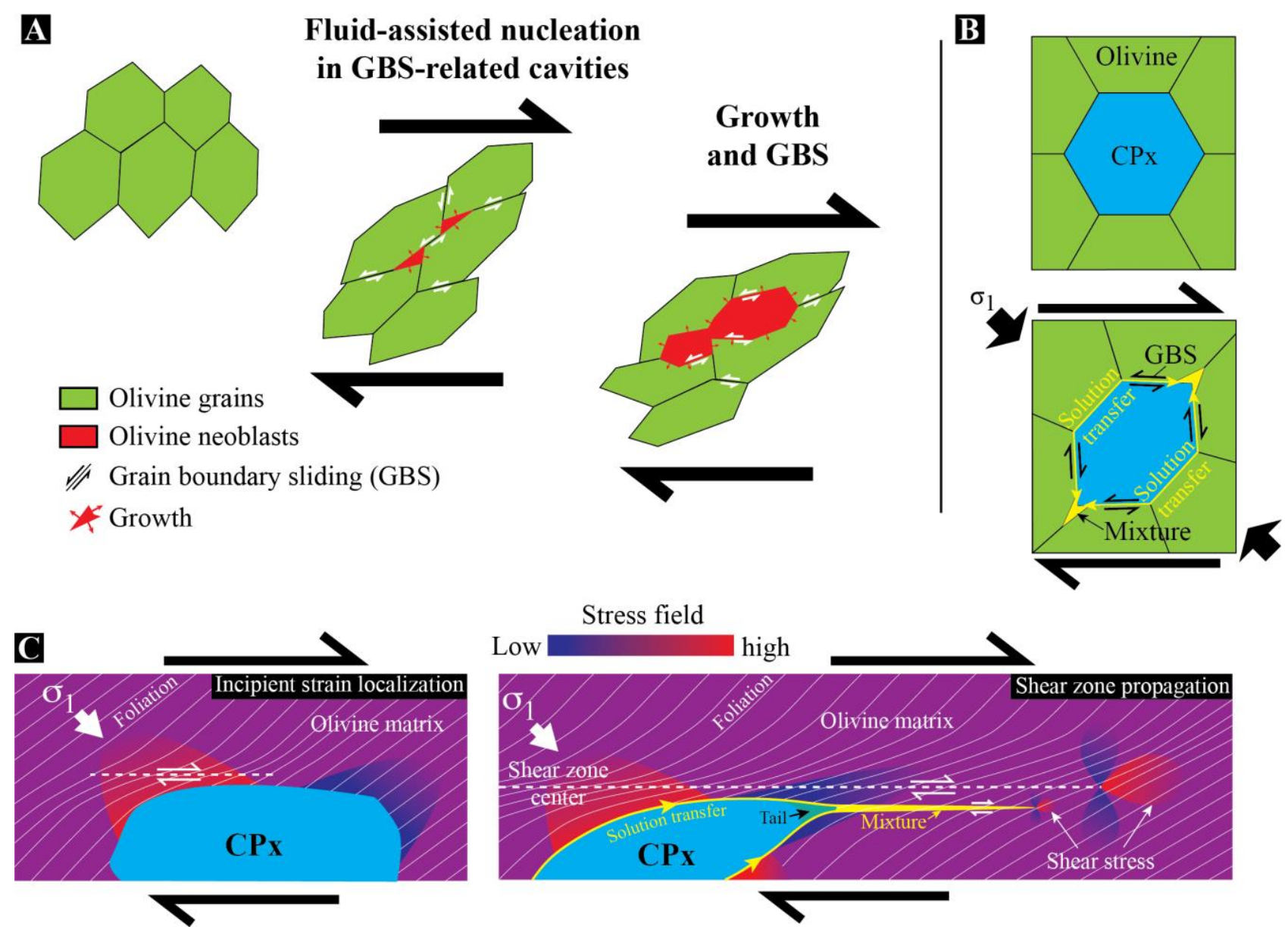
Table 1

\begin{tabular}{|c|c|c|c|c|c|}
\hline $\begin{array}{l}\text { Water } \\
\text { content } \\
\left.\text { (wt. ppm } \mathrm{H}_{2} \mathrm{O}\right)\end{array}$ & Hot-pressing & Peak stress & Pure olivine & $\begin{array}{c}\text { Two-phase } \\
\text { (fine-grained } \\
\text { CPx) }\end{array}$ & $\begin{array}{c}\text { Two-phase } \\
\text { (coarse-grained } \\
\text { CPx) }\end{array}$ \\
\hline Olivine matrix & $\begin{array}{l}597.2 \pm 76 \\
532.26 \pm 68 \\
532.15 \pm 60 \\
459.62 \pm 48 \\
505.29 \pm 50 \\
729.38 \pm 55 \\
\text { (amph.) } \\
347.53 \pm 478 \\
306.44 \pm 54\end{array}$ & $\begin{array}{l}684.26 \pm 54 \\
935.09 \pm 49 \\
\text { (amph.) } \\
693.32 \pm 61\end{array}$ & $\begin{array}{l}370.09 \pm 47 \\
526.20 \pm 55 \\
368.08 \pm 47 \\
461.07 \pm 49 \\
424.32 \pm 64\end{array}$ & \begin{tabular}{|l}
$707.94 \pm 48$ \\
$396.15 \pm 49$ \\
$479.78 \pm 497$ \\
$509.05 \pm 46$ \\
$614.57 \pm 50$ \\
$912.9 \pm 52$ \\
(amph.) \\
$773.23 \pm 60$ \\
$476.21 \pm 49$ \\
$786.47 \pm 83$ \\
$474.63 \pm 48$ \\
$546.59 \pm 59$ \\
$649.04 \pm 59$
\end{tabular} & $\begin{array}{l}421.28 \\
445.48 \\
442.37 \\
528.25 \\
544.00 \\
1115.43 \text { (amph.) } \\
1009.8 \text { (amph.) } \\
824.74 \\
661.00 \\
1034.74 \text { (SZ) } \\
1156.76 \text { (SZ) } \\
1283.67 \text { (SZ) }\end{array}$ \\
\hline Single olivine grain & & & & $157.25 \pm 44$ & \\
\hline Single CPx grain & $\begin{array}{l}148.85 \pm 61 \\
147.48 \pm 61 \\
209.57 \pm 63 \\
317.81 \pm 67 \\
184.64 \pm 63 \\
244.31 \pm 62\end{array}$ & $\begin{array}{l}160.55 \pm 64 \\
150.00 \pm 62 \\
314.47 \pm 64 \\
129.6 \pm 61\end{array}$ & $\begin{array}{l}684.26 \pm 54 \\
935.09 \pm 49 \\
\text { (amph.) } \\
693.32 \pm 61\end{array}$ & $166.60 \pm 45$ & $\begin{array}{l}436.66 \pm 72(\mathrm{SZ}) \\
648.1 \pm 78(\mathrm{SZ}) \\
477.89 \pm 64(\mathrm{SZ}) \\
473.51 \pm 126(\mathrm{SZ})\end{array}$ \\
\hline
\end{tabular}

